\title{
GASTRIC PROTEOLYSIS IN DISEASE
}

\section{PROTEINASE ACTIVITY OF EXTRACTS OF HUMAN GASTRIC ADENOCARCINOMATA}

\author{
BY \\ W. H. TAYLOR* \\ From the Department of Clinical Biochemistry, Radcliffe Infirmary, University of Oxford
}

(RECEIVED FOR PUBLICATION FEBRUARY 24, 1960)

\begin{abstract}
Resting gastric juice and extracts of uninvaded gastric mucosa from the stomachs of patients with gastric adenocarcinomata digest plasma protein with either two or three maxima below

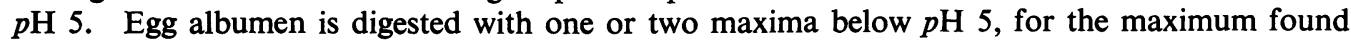
near $p \mathrm{H} 3.5$ with plasma protein is absent. These properties do not differ significantly from those described in normal subjects.

Extracts of gastric adenocarcinomatous tissue from the same patients differ in that plasma protein is digested with only one maximum, at $p \mathrm{H} 3.2$ to 3.4 , and egg albumen is not digested at all.

The proteinase activity of the carcinomatous tissue probably arises from adenocarcinomatous cells and not from invaded muscle cells or reactive fibrous tissue.

These results could be explained either $(a)$ if gastric adenocarcinomatous cells synthesized a quite different proteinase from those of normal gastric mucosa, or $(b)$ if they synthesized a proteinase, which resembled those of normal mucosa in possessing the active centre responsible for maximal activity near $p \mathrm{H} 3.5$ but in which the centre or centres responsible for maximal activity below $p \mathrm{H} \mathrm{3}$, were missing.
\end{abstract}

Greenstein and Stewart (1942) found that extracts of experimentally induced gastric adenocarcinomata from mice had no proteolytic action upon horse serum and egg albumen at $p \mathrm{H} 1.39$ and 5.03, whereas normal mouse gastric mucosa was active at the lower $p \mathrm{H}$. Apart from this work there appears to be little known about the proteolytic activity of gastric carcinomata. The experiments that are to be described compare the proteinase activity of adenocarcinomata from the stomachs of eight patients with the activity of adjacent uninvaded gastric mucosa and, in some instances, with the activity of gastric juice and of omental lymph glands containing metastases.

\section{Methods}

The methods used to determine proteinase $p \mathrm{H}$ activity curves have been described previously (Taylor, 1956, 1959a). Stomachs with carcinoma were obtained immediately after surgical removal, and cooled to below $5^{\circ} \mathrm{C}$. Gastric mucous membrane remote from the neoplasm was cut away and extracted in $2 \%(\mathrm{w} / \mathrm{v})$ sodium chloride. Care was taken in preparing the carcinomatous extract to exclude normal

\footnotetext{
*Present address: Department of Chemical Pathology, United *Present address: Department of Chemical Pat
Liverpool Hospitals, Ashton Street, Liverpool, 3 .
}

mucosal cells by taking a core from the centre of the ulcerated surface through the thickness of the growth into the muscle coat. As much muscle as possible was cut away, but clearly these extracts contain not only adenocarcinomatous cells but also invaded muscle cells and fibrous reactive tissue.

\section{Results}

Uninvaded Gastric Mucosa. - Extracts of uninvaded mucosa from five patients digested plasma protein below $p \mathrm{H} 5$ with two maxima at

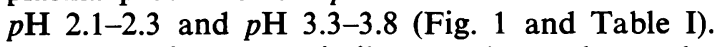
These maxima are similar to those shown by gastric mucosal extracts of most normal subjects (Taylor, 1956, 1959a). In two patients (Nos. 5 and 6) three maxima occurred, in the $p \mathrm{H}$ ranges $1.5-$ $2.1,2.6-2.8$, and $3.5-3.6$, resembling the maxima shown by a minority (about $15 \%$ ) of normal subjects and by a majority of patients with peptic ulcer (Taylor, 1959b). The eighth patient gave a curve with two maxima, at $p \mathrm{H} 1.6$ and 3.1 , which resembled curves obtained from extracts of normal pyloric mucosa (Taylor, 1959c).

The $p \mathrm{H}$ activity curves for the digestion of egg albumen were determined in four patients (Fig. 2, Table I) and the results again resemble those 
TABLE I PROTEOLYTIC ACTIVITY OF GASTRIC JUICE AND OF EXTRACTS OF UNINVADED MUCOSA, OF ADENOCARCINOMATA, AND OF LYMPH GLANDS CONTAINING METASTASES IN EIGHT PATIENTS WITH CARCINOMA OF THE STOMACH

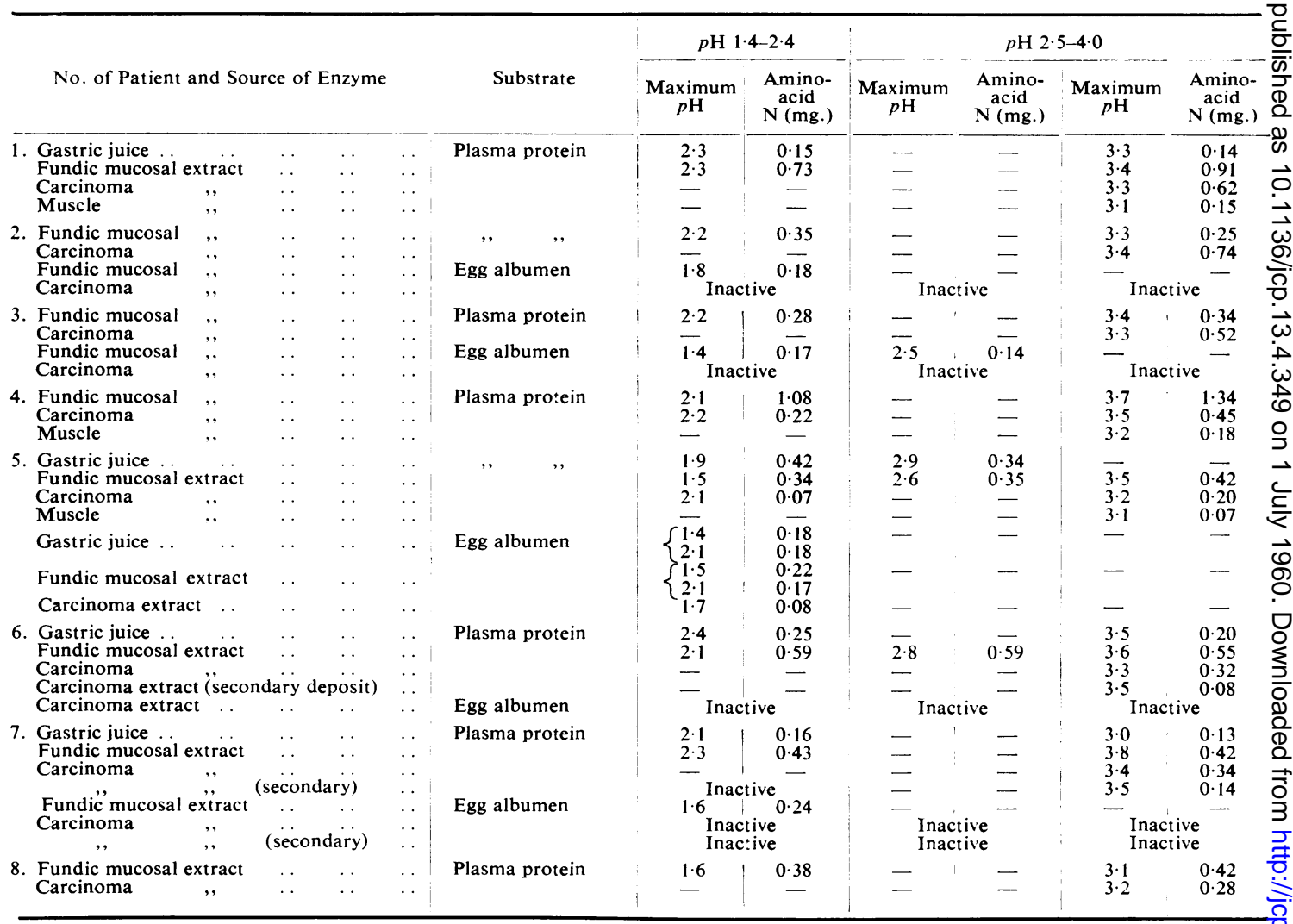

In the tables and figures the amount of liberated amino-acid $\mathrm{N}$ is that of the whole digest, which consisted of $4 \mathrm{ml}$. buffer, $0.5 \mathrm{ml}$. or $1 \mathrm{ml}$. of gastric extract, and $1 \mathrm{ml}$. of plasma or of $5 \% \mathrm{egg}$ albumen.

described in normal subjects, in that the maximum seen with plasma protein at $p \mathrm{H} 3.3$ to 3.8 did not occur. Thus a single maximum at $p \mathrm{H} 1.4$ to 1.8 or two maxima, the second at $p \mathrm{H} 2.1$ to 2.5 , were seen.

Carcinomatous Extracts.-In contrast to the uninvaded mucosa, carcinomatous extracts from six patients digested plasma protein with only a single maximum at $p \mathrm{H} \mathrm{3.2-3.4}$ (Table I, Fig. 2). The degree of digestion at $p \mathrm{H} 2$ was slight, ranging from 0 to $40 \%$ of that at the maximum. One patient (No. 5) gave in addition a slight, just significant, maximum at $p \mathrm{H} 2.1$ which was thought to arise from contamination with uninvaded mucosal cells. The remaining patient (No. 4) differed from the others in that the carcinoma had invaded, but not ulcerated, the mucosal surface, so that normal cells were included in the extract. The resulting $p \mathrm{H}$ activity curve did not differ significantly from that of the uninvaded mucosa.

The carcinomatous extracts also differed from $\stackrel{\circ}{ᄀ}$ those of uninvaded mucosa in that four of the $\frac{D}{0}$ five extracts tested failed completely to attack egg albumen between $p \mathrm{H} 1$ and $p \mathrm{H} 5$ (Fig. 2 and $\stackrel{N}{\circ}$ Table I). One extract (from patient No. 5), which N is thought to have contained material from $N$ uninvaded mucosal cells, gave a slight maximum at 1.7 .

Gastric Juice.-The resting juice of two patients (Nos. 1 and 6) digested plasma protein with two $\stackrel{9}{?}$ maxima at $p \mathrm{H} 2.3$ to 2.4 and $p \mathrm{H} 3.3$ to 3.5 and 0 thus resembled the gastric juice of normal subjects. In two other patients two maxima were also $\stackrel{\mathbb{D}}{\mathbb{D}}$ shown, but at lower hydrogen ion concentrations, $\frac{\vec{\Phi}}{\Phi}$ $p \mathrm{H} 1.9$ to 2.1 and $p \mathrm{H} 2.9$ to 3.0. The gastric $\frac{2}{\sigma}$ juice in these cases behaved like normal pyloric mucosal extracts (Taylor, 1959c). 


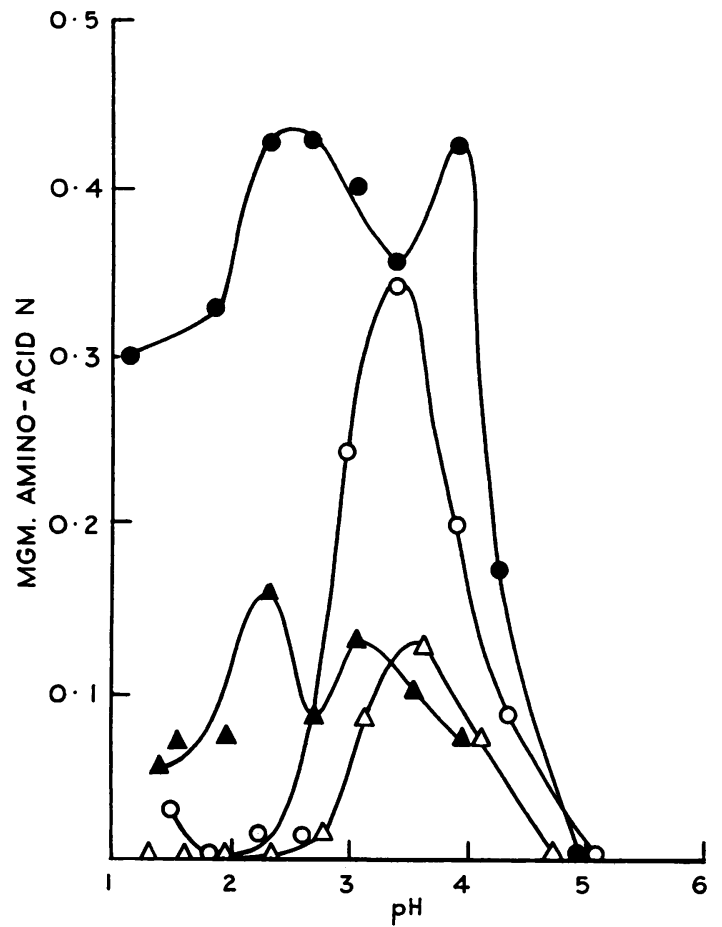

FIG. 1.-Curves of $p \mathbf{H}$ activity for the digestion of plasma protein by the resting gastric juice $(\boldsymbol{\Lambda})$, by an extract of uninvaded fundic mucosa (O), by an extract of gastric adenocarcinoma (O), and by an extract from a lymph gland containing secondary deposit $(\triangle)$ from a patient with cancer of the stomach. At $37^{\circ} \mathrm{C}$. for three hours.

Lymph Glands with Metastases.-In two patients (Nos. 6 and 7) it was possible to examine omental lymph glands which were almost totally invaded by secondary metastatic adenocarcinomatous cells (Table I, Fig. 1). In both, the extract of the gland digested plasma protein with a single maximum at $p \mathrm{H} 3.5$ which closely resembled the maxima seen with the extracts of the primary growths. In one of these patients the lymph gland extract failed to digest egg albumen, again resembling the primary growth. These observations suggest that the proteinase activity of the primary and secondary growths is similar and would support the view that the activity arises from the adenocarcinomatous cells. It has unfortunately not been possible to obtain normal human lymph glands as a control for these observations.

Gastric Muscle.-Since the adenocarcinomatous extracts are almost always contaminated with material derived from invaded smooth muscle cells, their proteinase activity may perhaps arise from these and not from the carcinomatous cells themselves. In three patients, smooth muscle from uninvaded parts of the stomach was extracted in the same manner as the adenocarcinomata and its proteinase activity investigated. The extracts gave slight proteolytic maxima, at $p \mathrm{H} 3.1$ and 3.2. In each instance, however, the activity exerted by these purely muscle extracts was only about one-third of that exerted by the carcinomatous extracts, in which the proportion of material derived from smooth muscle must be relatively small. Consequently it is likely that the proteinase activity of the adenocarcinomatous extracts does not arise principally from invaded muscle cells.

Fibrous Tissue. - The adenocarcinomatous extracts also contain material from fibrous reactive tissue, and this, too, might perhaps possess proteinase activity. Fibrous tissue cannot be isolated from the growth itself, but it was possible to obtain from another patient a workable quantity of fibrous tissue from the base of a large benign chronic gastric ulcer. The extract of this fibrous tissue was devoid of proteinase activity at $p \mathrm{H} 1$ to 5 when tested upon plasma protein and egg albumen. This observation suggests that reactive fibrous tissue does not contribute to the proteinase activity of the carcinomatous extracts.

Inhibiting Substances. - The absence of a proteolytic maximum near $p \mathrm{H} 2$ with adenocarcinomatous extracts might perhaps be caused by an inhibiting substance in the extracts. No inhibition of the activity of normal gastric juice or of crystalline swine pepsin at $p \mathrm{H} 2$ was observed when these materials were incubated with carcino-

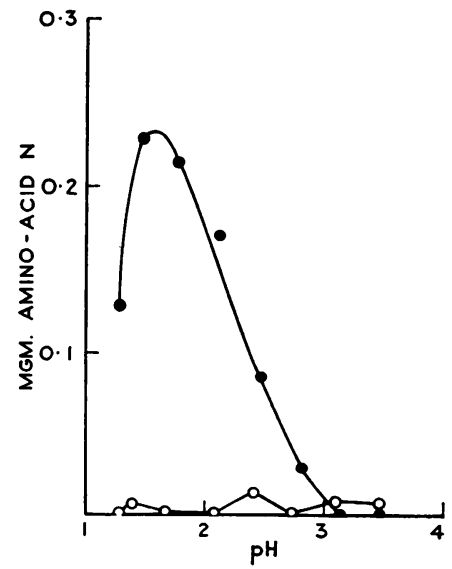

FIG. 2.-Curves of $p \mathrm{H}$ activity for the digestion of egg albumen by an extract of uninvaded fundic mucosa $(\bullet)$ and by an extract of gastric adenocarcinoma $(0)$ from the same patient as in Fig. 1. At $37^{\circ} \mathrm{C}$. for three hours. 
matous extract, with dialysed extract, with dialysate from the extract, or with fractions from the extract obtained by ammonium sulphate precipitation.

\section{Discussion}

The results reveal one outstanding difference between the proteinase activity of human gastric adenocarcinomata and that of uninvaded gastric mucosa, namely, the absence, with both plasma protein and egg albumen as substrates, of a digestion maximum near $p \mathrm{H} 2$. The evidence that the activity of the carcinomata arises from the adenocarcinomatous cells themselves, and not from invaded muscle fibres or reactive fibrous tissue, is very suggestive rather than conclusive, but the absence of the $p \mathrm{H}$ maximum near $p \mathrm{H} 2$ is independent of any uncertainty on this account, for the tumours contained sufficient adenocarcinomatous cells for their extracts to have shown this maximum had they been elaborating the normal enzyme.

If the evidence be accepted that the proteinase responsible for the $p \mathrm{H}$ maximum at $p \mathrm{H} 3.2$ to 3.4 comes from the adenocarcinomatous cells, the question arises as to the relationship of the maximum to that occurring in the same $p \mathrm{H}$ range with uninvaded mucosa and with gastric juice. The results indicate that the uninvaded mucosal extracts and gastric juice exhibit a wider range of $p \mathrm{H}$ maximum ( $p \mathrm{H} 2.9$ to $p \mathrm{H} 3.8$ ) than is exhibited by the carcinomatous extracts ( $p H$ 3.23.4), though this difference might be accounted for by the fact that the uninvaded mucosal extracts and gastric juice contain varying proportions of two proteinases, one from the chief cells of the body of the gastric glands, which in the normal subject exhibits $p \mathrm{H}$ maxima at $p \mathrm{H} 1.8$ to 2.4 and $p \mathrm{H} 3.4$ to 3.9, and the other from the neck chief cells and from the pyloric glands, exhibiting maxima at $p \mathrm{H} 1.5$ to 1.9 and $p \mathrm{H} 3.0$ to 3.4 (Taylor, 1959c). One strong point of resemblance between the enzymes from carcinomatous tissue and those of the uninvaded mucosa is their inability to attack egg albumen when the $p \mathrm{H}$ iso above 3.0.

There is evidence (Taylor, 1959d) that the two $\overline{\bar{s}}$. proteolytic $p \mathrm{H}$ maxima exhibited by each of the two normal proteinases of gastric juice and gastric mucosal extracts result from the activity of two active centres on each enzyme. It is possible thato the centre responsible for activity around $p \mathrm{H} 3.5$ is essentially similar, structurally, in the enzymes from normal tissue and in that from carcinoma $=$ tous tissue, and that, in the absence of a demon--. strable inhibitor, the loss of the maximal activity at $p \mathrm{H} 2$ arises from an inability of the adeno- $\dot{\omega}$ carcinoma cell to synthesize an enzyme with two $\stackrel{0}{0}$ active centres. The alternative explanation wouldo be that the proteinase in gastric carcinomatous extracts is unrelated to those of normal gastric
mucosa.

Whether gastric adenocarcinomata arise from $\vec{\circ}$ normally differentiated gastric cells which undergo neoplastic change, or from undifferentiated cells which undergo neoplastic change, it seems that theo absence of a proteolytic maximum near $p \mathrm{H} 25$ represents a difference between a neoplasm and the tissue from which it is derived and poses $a \frac{\Phi}{\varnothing}$ problem which requires a biochemical answer.

I wish to thank Miss Barbara Hunt and Miss Anne 3 Catesby for skilled assistance, the surgeons of the $\mathcal{\supset}$ Radcliffe Infirmary for providing gastrectomy material, and Mr. J. R. P. O'Brien and Professor R. B. Fisher for reading the D.M. thesis which contained a응 preliminary report of these observations. I am:grateful to the Medical Research Council for their. partial support of this work by a grant for technicalo assistance.

\section{ReferenCes}

Greenstein, J. P., and Stewart, H. L. (1942). J. nat. Cancer Inst., 2, 631.

Taylor, W. H. (1956). D.M. thesis, University of Oxford.

(1959a). Biochem. J., 71, 73.

- (1959b). J. clin. Path., 12, 338.

(1959c). Biochem. J., 71, 384.

(1959d). Ibid., 71, 373 . 